E3S Web of Conferences 1, 01006 (2013)

DOI: $10.1051 / \mathrm{e} 3$ sconf/20130101006

(c) Owned by the authors, published by EDP Sciences, 2013

\title{
Effects of Chemical Applications to Metal Polluted Soils on Cadmium Uptake by Rice Plant
}

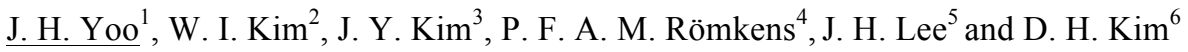 \\ ${ }^{1}$ Department of Agro-Food Safety, National Academy of Agricultural Science, Rural Development Administration, \\ Republic of Korea, idisryu@korea.kr \\ ${ }^{2}$ Department of Agro-Food Safety, National Academy of Agricultural Science, Rural Development Administration, \\ Republic of Korea,wikim721@korea.kr \\ ${ }^{3}$ Department of Agro-Food Safety, National Academy of Agricultural Science, Rural Development Administration, \\ Republic of Korea,jykim98@korea.kr \\ ${ }^{4}$ Soil Science Center, Alterra, Wageningen UR, the Netherlands, paul.romkens@wur.nl \\ ${ }^{5}$ Department of Agro-Food Safety, National Academy of Agricultural Science, Rural Development Administration, \\ Republic of Korea,jhlee76@korea.kr \\ ${ }^{6}$ Department of Agro-Food Safety, National Academy of Agricultural Science, Rural Development Administration, \\ Republic of Korea, kdho@korea.kr
}

\begin{abstract}
Pot experiment using metal polluted soils was conducted to investigate the effects of lime, iron and sulfur on changes in $\mathrm{Cd}$ availability and uptake by rice plant. Drainage and irrigation of water were performed to develop redox changes like field cultivation. Iron chloride and sodium sulfate solutions were applied to the pots in the middle of growth period of rice plant. Reactive metal pool in heavily polluted soils was slightly decreased after treatments with lime, iron chloride, sodium sulfate and combination of these chemicals. However, cadmium uptake by rice plant was significantly different across the treatments and the extent of $\mathrm{Cd}$ pollution. For highly polluted soils, more $\mathrm{Cd}$ reduction was observed in iron chloride treatments. $\mathrm{Cd}$ content in polished rice for iron chloride and (iron chloride+organic matter) treatments was only 16-23\% and $25-37 \%$ compared to control and liming, respectively. Treatment of (iron chloride+sulfate) rather increased $\mathrm{Cd}$ content in rice. For moderately polluted soils, $\mathrm{Cd}$ reduction rate was the order of $(\mathrm{OM}+$ iron chloride $)>$ iron chloride $>$ lime. Other treatments including sulfate rather increased $\mathrm{Cd}$ content in rice maximum 3 times than control. It was proposed to determine the optimum application rate of iron for minimizing hazardous effect on rice plant.
\end{abstract}

Key words: Heavy metal, soil, sulfur, iron, cadmium, rice

\section{Introduction}

Food safety issues related to heavy metal contamination have attained national attention since mid-90s in South Korea. There are about 1,000 abandoned metal mines in South Korea. The area of cropland near the mines (mainly paddy fields) is around 34,000 ha and about $14 \%$ of that area is polluted with heavy metals exceeding soil quality standards. Generally, soil covering with new soil is conducted by the government after prohibiting cropping for the agricultural fields that exceed food quality standard. However, that work is nationwide, cost high, comes with degradation of soil fertility and may take a few years. So, the application of some chemicals to polluted soils to reduce the bioavailability of heavy metals could be an alternative to the traditional soil improvement.

Some physical or chemical methods have been conducted to ensure crop safety or to increase the rate of utilization of farmlands polluted with heavy metals. One of the chemical stabilization methods of heavy metals is to input agricultural materials to polluted soils for decreasing the solubility of heavy metals in soils (Vangronseld et al., 1998) and lime application is a relevant and easy method especially for acidic soils contaminated with heavy metals. In addition to lime, iron chloride and/or sulfate can have potentials for enhancing formation of sulfides and consequently controlling solubility and stability of heavy metals when applied to paddy soils which have redox changes. This concept 
could be supported by some findings with respect to fundamental soil chemical processes. In view of sulfide formation in anoxic condition like paddy soils, immobilization of metals through the formation of metal sulfide and consequently reduced solubility of metals might be attained by the addition of iron chloride and/or sulfate to metal polluted soils. Many researchers have reported the role of sulfide linked to decrease in metal solubility in reducing conditions through the formation of iron sulfide or metal sulfide (Afonso 1992, Di Toro et al. 1992, Kirk 2004, Morse et al. 1999, Reddy et al. 2008). Another idea or aim of the treatment of iron chloride and sulfate is to lengthen the stability of metal sulfides in case of changes in soil conditions from anoxic to oxic like paddy fields because metals sequestered in metal sulfides may release to solution phase in oxic condition (Morse, 1995).

Objectives of this study are to investigate the effects of iron chloride and/or sulfate on changes in solubility of metals in paddy soils having redox changes and to evaluate the feasibility of application of the chemicals to paddy soils polluted with heavy metals for the purpose of reducing metal uptake by rice plant.

\section{Materials and Methods}

Pot experiment was performed in greenhouse using rectangular rubber pots. In 2011, a series of paddy soils having pollution gradient of heavy metals (1.9-8.7 $\mathrm{mg}$ $\mathrm{kg}^{-1}$ for total $\mathrm{Cd}$ ) were collected from paddy fields near abandoned metal mine at Southern part of South Korea. Soils were air-dried, passed through a $4 \mathrm{~mm}$ sieve and filled in each pot at height of about $20 \mathrm{~cm}$. In each pot, 2 rhizon samplers were installed horizontally at $12.5 \mathrm{~cm}$ high from the bottom of the pot. Treatments were control, lime, $\mathrm{FeCl}_{2} \cdot 4 \mathrm{H}_{2} \mathrm{O}, \quad\left(\mathrm{FeCl}_{2} \cdot 4 \mathrm{H}_{2} \mathrm{O}+\mathrm{Na}_{2} \mathrm{SO}_{4}\right), \quad \mathrm{Na}_{2} \mathrm{SO}_{4}$, (organic matter(compost) $+\mathrm{FeCl}_{2} \cdot 4 \mathrm{H}_{2} \mathrm{O}$ ) and (compost $+\mathrm{FeCl}_{2} \cdot 4 \mathrm{H}_{2} \mathrm{O}+\mathrm{Na}_{2} \mathrm{SO}_{4}$ ). Lime and compost were initialy mixed with soils before filling the pots. Pots were flooded with water at $3 \mathrm{~cm}$ height from the soil surface and incubated before transplanting of rice plant. On June 22, 4 rice plants were transplanted to each pot and water level was maintained periodically. Fertilization and water control including drainage and irrigation were conducted in more or less the same manner as field cultivation. On August 2, water was drained to develop oxic condition mimicking the situation of paddy field, midsummer drainage. Iron chloride and sodium sulfate solutions were prepared using distilled water. Concentration of each solution was $25 \mathrm{mM}$ and $10 \mathrm{~L}$ of the solution was irrigated to each pot on the basis of each treatment on August 12. For treatments of control and lime, water was irrigated. After the first solution irrigation, intermittent irrigation of water was performed until September 7. On September 8, sodium sulfate solutions were irrigated again only for the treatments of $\left(\mathrm{FeCl}_{2} \cdot 4 \mathrm{H}_{2} \mathrm{O}+\mathrm{Na}_{2} \mathrm{SO}_{4}\right)$, $\mathrm{Na}_{2} \mathrm{SO}_{4}$ and (compost $+\mathrm{FeCl}_{2} \cdot 4 \mathrm{H}_{2} \mathrm{O}+\mathrm{Na}_{2} \mathrm{SO}_{4}$ ) and water was irrigated for other treatments. Water level was maintained by replenishing water periodically at $3 \mathrm{~cm}$ height from the soil surface until harvest.

Total 10 sampling events of soil solutions were conducted to monitor changes in metal content and chemical properties such as $\mathrm{pH}$ and EC using rhizon samplers and vacuum tubes from one week after transplanting of rice until October 6 and the sampling interval was about 10 days. Metal content in soil solutions was measured by ICP-MS after filtration using $0.45 \mu \mathrm{m}$ syringe filter. Rice was harvested on October 25 and dried to grind rice grains. Metal concentration in polished rice was measured using ICP-MS after acid digestion with microwave assisted apparatus. Growth and development of rice plant was also investigated during vegetative period.

\section{Results and Discussion}

Reactive metal pool in heavily polluted soils was slightly decreased after treatments with lime, iron chloride, sodium sulfate and combination of these chemicals and there was little change in moderately polluted soils as shown in table 1.

Table 1. Changes in extractable cadmium content in soils after treatments $\left(\mathrm{mg} \mathrm{kg}^{-1}\right)$

\begin{tabular}{llll}
\hline Treatment & $\begin{array}{l}\text { Highly } \\
\text { soil }\end{array}$ & polluted & $\begin{array}{l}\text { Moderately } \\
\text { polluted soil }\end{array}$ \\
\hline Control & 6.9 & 2.6 \\
Lime & 6.3 & 2.6 \\
$\mathrm{IC}^{\mathrm{a}}$ & 6.7 & 2.5 \\
$\mathrm{IC}+\mathrm{SS}^{\mathrm{b}}$ & 5.9 & 2.7 \\
$\mathrm{SS}$ & 5.7 & 2.5 \\
$\mathrm{OM}^{\mathrm{c}}+\mathrm{IC}$ & 6.1 & 2.6 \\
$\mathrm{OM}+\mathrm{IC}+\mathrm{SS}$ & 6.4 & 2.7 \\
\hline
\end{tabular}

${ }^{\mathrm{a}}$ Iron chloride.

${ }^{\mathrm{b}}$ Sodium sulfate.

${ }^{\mathrm{c}}$ Organic matter.

Total cadmium content was 8.7 and $3.8 \mathrm{mg} \mathrm{kg}^{-1}$ for highly polluted and moderately polluted soils, respectively. However, cadmium uptake by rice plant was significantly different across the treatments and soils (Figure 1 and 2).

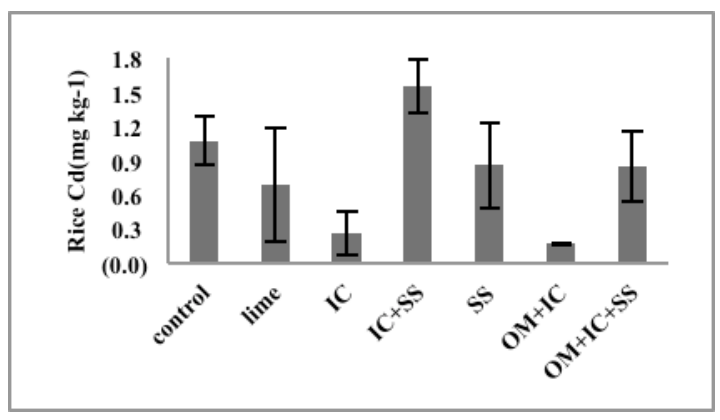

Figure 1. Cadmium content in polished rice harvested on heavily polluted soils depending on the treatments 


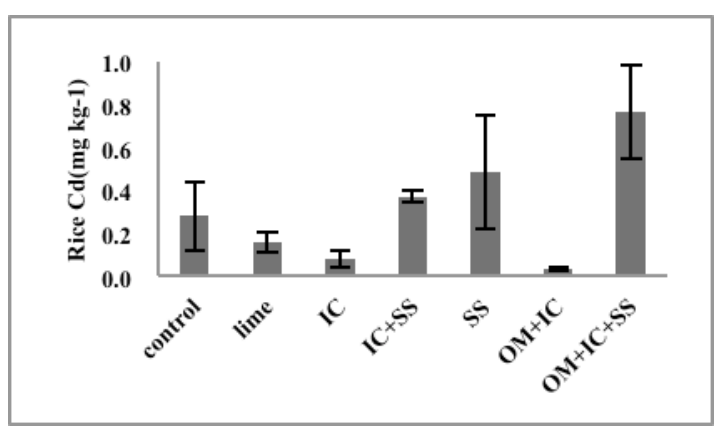

Figure 2. Cadmium content in polished rice harvested on moderately polluted soils depending on the treatments

For highly polluted soils, though lime and sulfate treatments also reduced cadmium content in rice, more reduction was observed in iron chloride treatments. Cadmium content in polished rice for iron chloride and (iron chloride+organic matter) treatments was only $16-23 \%$ compared to control and $25-37 \%$ compared to lime treatment, consequently it met Korean food quality standard for polished rice $\left(0.2 \mathrm{mg} \mathrm{kg} \mathrm{kg}^{-1}\right)$ or slightly exceeded (0.17-0.25 mg kg-1). Treatment of (iron chloride+sulfate) rather increased cadmium content in rice. For moderately polluted soils, Cd reduction rate was the order of $(\mathrm{OM}+$ iron chloride $)>$ iron chloride $>$ lime and $\mathrm{Cd}$ content in rice for lime treatment was 2-4 time more than iron chloride and (OM+iron chloride) treatments though lime treatment also met the food quality standard. Other treatments including sulfate rather increased $\mathrm{Cd}$ content in rice maximum 3 times than control.

With respect to the effect of sulfur treatment on $\mathrm{Cd}$ uptake by plant, there are controversial results among researchers supporting increase in $\mathrm{Cd}$ content in plants after sulfur treatment or vice versa (Fan et al., 2010), however, our results shows that sulfate addition (alone or combination with other treatment) to paddy soils rather increases $\mathrm{Cd}$ uptake by rice plant. This could be attributed by decrease in $\mathrm{pH}$ resulting from sulfate addition and consequent increase in $\mathrm{Cd}$ solubility and by the lack of metal sulfide formation because of locally oxic condition in studied soils facilitated by the drain of water in ripening stage of rice plant, compared to the study ensuring CdS precipitation (Kashem et al., 2001) resulting from flooded condition for whole growth period of rice. Our result is also in contradiction to the result that sulfur supply to waterlogged paddy soil significantly decreased Cd content in brown rice (Fan et al., 2010). Fan et al. also reported that sulfur application decreased iron plaque formation on the roots and consequently increased $\mathrm{Cd}$ content in roots of rice plant.

Iron plaque, iron oxides or hydroxides on the roots of plants sequesters metals by adsorption or co-precipitation, consequently effects on the metal availability and uptake by plants (Liu et al., 2007). As shown in present study, significant effect of iron chloride addition including combination with organic matter on reduction of $\mathrm{Cd}$ uptake by rice could be affected by the formation of iron plaque in rhizosphere enhanced by excessive iron supply and locally oxidizing condition.
This could be supported by the report that soluble iron and locally oxidizing condition are needed to form iron plaque on roots (Crowder et al., 1991). After iron chloride application, brown color on leaves of rice plant like bronzing and red-brown deposits on soil surface were developed at present study. This symptom was also reported by Liu et al. (2007) who supplied ferrous sulfate to rice plant. Therefore, it would be more practical to determine the optimum application rate of iron to minimize any hazardous effect on rice plant for ensuring rice yield.

\section{Conclusion}

The results from present study suggested that iron chloride (or with organic matter) application to metal polluted soils could significantly decreased $\mathrm{Cd}$ uptake by rice than liming, however, sulfate addition rather increased the uptake. The adverse effect of sulfate may be ascribed to the redox change in paddy soils after drainage. It would be more practical to determine the optimum application rate of iron chloride to paddy soils for minimizing hazardous effect on rice plant and maximizing $\mathrm{Cd}$ uptake by rice simultaneously.

\section{Acknowledgements}

The work was jointly supported by the Rural Development Administration of South Korea (Project PJ006338 in 2011 and PJ008650 in 2012).

\section{References}

Kirk G. The biogeochemistry of submerged soils. John Wiley \& Sons, Ltd: Chichester, 2004; p 282.

Morse JW, Luther GW.III. Chemical influences on trace metal-sulfide interactions in anoxic sediments. Geochim. Cosmochim. Acta 1999; 63:3373-3378.

Afonso, MD, Stumm, W. Reductive dissolution of Fe(III) (hydr)oxides by hydrogen-sulfide. Langmuir 1992; 8:1671-1675.

Di Toro DM, Mahony JD, Hansen DJ, Scott KJ, Carlson AR and Ankley GT. Acid volatile sulfide predicts the acute toxicity of cadmium and nickel in sediments. Environ. Sci. Technol. 1992; 26:96-101.

Reddy KR, DeLaune RD. 2008, Biogeochemistry of wetlands: Science and applications. CRC Press, Boca Raton.

Morse JW. In Metal Contaminated Aquatic Sediments; Allen HE, Ed.; Ann Arbor Press: Ann Arbor, MI, 1995; Chapter 8:187-199.

Kashem MA, Singh BR. 2001. Metal availability in contaminated soils: II. Uptake of $\mathrm{Cd}, \mathrm{Ni}$ and $\mathrm{Zn}$ in rice plants grown under flooded culture with organic matter addition. Nutrient Cycling in Agroecosystems 61:257-266.

Fan JL, Hu ZY, Ziadi N, Xia X, Wu CYH. Excessive sulfur supply reduces cadmium accumulation in brown rice (Oryza sativa L.). Environmental Pollution 2010; 158:409-415. 
Crowder AA, St.-Cyr L. Iron oxide plaque on wetland roots. Trends Soil Sci. 1991; 1:315-329.

Lai HY, Chen ZS. The influence of 2Na-EDTA application on the interactions of cadmium, zinc, and lead and their uptake of rainbow pink (Dianthus chinensis). J Hazardous Materials 2006;
137:1710-1718.

Liu HJ, Zhang JL, Zhang FS. Role of iron plaque in Cd uptake by and translocation within rice (Oryza sativa L.) seedlings grown in solution culture. Environmental and Experimental Botany 2007; 59:314-320. 